\title{
Response behaviour of oxygen sensing solid electrolytes
}

\author{
A. J. A. WINNUBST, A. H. A. SCHARENBORG, A. J. BURGGRAAF \\ Twente University of Technology, Department of Chemical Engineering, Laboratory for Inorganic \\ Chemistry and Materials Science, PO Box 217, 7500 AE Enschede, The Netherlands
}

Received 19 January 1984; revised 21 May 1984

The response time $\left(t_{\mathrm{r}}\right)$ after a step change in oxygen partial pressure was investigated for some solid electrolytes used in Nernst type oxygen sensors. The electrolyte as well as the (porous) electrode material affect the value of $t_{\mathrm{r}}$. Stabilized $\mathrm{Bi}_{2} \mathrm{O}_{3}$ materials exhibit slower response rates (larger $t_{\mathrm{r}}$ values) than stabilized $\mathrm{ZrO}_{2}$. Introduction of $\mathrm{Bi}_{2} \mathrm{O}_{3}$ in stabilized $\mathrm{ZrO}_{2}$ increases the response time.

Gold electrodes show a higher response rate than platinum in the oxygen partial pressure and temperature region used.

\section{Introduction}

Solid electrolytes which exhibit oxygen ion conductivity at intermediate temperatures are suitable for use in oxygen sensors. In most cases stabilized $\mathrm{ZrO}_{2}$ is used [1] in combination with noble metal electrodes. A potential difference $(E)$ between the electrodes of the sensor is developed when different oxygen partial pressures $P_{\mathrm{O}_{2}}^{\prime}$ and $P_{\mathrm{O}_{2}}^{\prime \prime}$ exist on each side of the sensor. According to Nernst the following relation holds:

$$
E=\frac{R T}{n F} \ln \left(P_{\mathrm{O}_{2}}^{\prime} / P_{\mathrm{O}_{2}}^{\prime \prime}\right)
$$

The response time is defined as the time lag between a step change in bulk oxygen partial pressure and the final value of $E$ registered by the sensor. Little attention is paid in the literature to quantitative measurement and analysis of the response time, $t_{\mathrm{r}}$, of oxygen sensors. This may be due to the fact that oxygen sensors are frequently used at high temperatures. At these temperatures $\left(\geqq 700^{\circ} \mathrm{C}\right)$ an electrochemical response time of a few milliseconds is calculated for stabilized $\mathrm{ZrO}_{2}$ [2]. In practical sensors the ultimate value of $t_{r}$ is larger and is governed by aerodynamic conditions and diffusion limitations.

Long-term e.m.f. changes were investigated at high temperatures $[3,4]$. These changes may arise because of different transport properties of impurity phases which have a lower oxygen transport number than the main phase. The rate limiting chemical diffusion process within the bulk of the electrolyte is many orders of magnitude slower than the equilibratory reaction at the electrode-electrolyte surface after a $P_{\mathrm{O}_{2}}$ step change. This long-term process results in a final potential change of a few per cent of the e.m.f. difference measured immediately after the $P_{\mathrm{O}_{2}}$ change [4] and can be seen as a secondary effect.

Anderson and Graves [5] have performed experiments on $\mathrm{ZrO}_{2}$ tubes with platinum paste electrodes and gas flow rates of $16-32 \mathrm{~cm}^{3} \mathrm{~s}^{-1}$. Here the diffusive mass transport from the bulk gas to the reaction sites at the sensor surface is rate determining. If higher gas flow rates and porous electrodes are used other processes can be studied such as the reactions at the electrode-electrolytegas interface. The electrodes of the sensor are often covered by a gas permeable membrane in order to prevent contamination of the electrodes. In this case the response time is also governed by the diffusion rate of the oxygen from the bulk gas to the electrode [6].

The materials used in this investigation were pure and $\mathrm{Bi}_{2} \mathrm{O}_{3}$-doped stabilized $\mathrm{ZrO}_{2}$ and stabilized $\mathrm{Bi}_{2} \mathrm{O}_{3}$. Well-defined and porous platinum or gold electrodes were used. In this way we com. pared stabilized $\mathrm{ZrO}_{2}$ used in commercial sensors with $\mathrm{Bi}_{2} \mathrm{O}_{3}$ based materials which exhibit a higher 
ionic conductivity [7] and a lower electrode resistance [8]. Furthermore the effect of the modification of yttria-stabilized zirconia with $\mathrm{Bi}_{2} \mathrm{O}_{3}$ was studied.

\section{Experimental method}

Yttrium stabilized $\mathrm{ZrO}_{2}(\mathrm{ZY})$ and erbium stabilized $\mathrm{Bi}_{2} \mathrm{O}_{3}(\mathrm{BE})$ were investigated. The composition of the electrolyte materials is given in Table 1. The $\mathrm{ZYB}$ samples are $\mathrm{Bi}_{2} \mathrm{O}_{3}$-doped $\mathrm{ZrO}_{2}-$ $\mathrm{Y}_{2} \mathrm{O}_{3}$ materials (ZY17 or ZY21). The ZYB1 sample is obtained from pure $\mathrm{ZY} 17$ treated for $2 \mathrm{~h}$ in a $\mathrm{Bi}_{2} \mathrm{O}_{3}$ atmosphere. The other ZYB samples contain a certain percentage of $\mathrm{Bi}_{2} \mathrm{O}_{3}$ in the bulk phase. The $\mathrm{ZYB} 2$ is a monophasic $\mathrm{Bi}_{2} \mathrm{O}_{3}$ doped specimen which does not contain any monoclinic $\mathrm{ZrO}_{2}$ [9]. The $\mathrm{Bi}_{2} \mathrm{O}_{3}$ is stabilized with different amounts of $\mathrm{Er}_{2} \mathrm{O}_{3}$ (BE samples in Table 1). After isostatic pressing and sintering all samples exhibit a theoretical density of $95 \%$ or more. The electrolytes used for response measurements have a diameter of about $10 \mathrm{~mm}$ and a thickness of 1 $2 \mathrm{~mm}$. The electrodes were sputtered on the polished electrolyte surfaces. The method has been published elsewhere [8] and results in well-defined porous electrodes.

The sensors obtained in this way were used for the response time measurements performed in the cell which is schematically given in Fig. 1 . The sensor (1) is placed on an $\mathrm{Al}_{2} \mathrm{O}_{3}$ ring (3). This ring, with a Pt paste electrode on the top, is placed in a

Table 1. Composition of the investigated materials

\begin{tabular}{lllll}
\hline Sample number & \multicolumn{5}{l}{ Composition (mol \%) } \\
\cline { 2 - 5 } & $\mathrm{ZrO}_{2}$ & $\mathrm{YO}_{1,5}$ & $\mathrm{BiO}_{1.5}$ & ErO $_{1,5}$ \\
\hline $\mathrm{ZY17}$ & 83 & 17 & - & - \\
$\mathrm{ZY21}$ & 79 & 21 & - & - \\
$\mathrm{ZYB1}$ & 83 & 17 & $?^{*}$ & - \\
$\mathrm{ZYB2}$ & 78 & 20.6 & 1.4 & - \\
$\mathrm{ZYB3}^{\dagger}$ & 78.3 & 20.7 & 1 & - \\
$\mathrm{ZYB}^{\dagger}$ & 79.5 & 16.3 & 4.2 & - \\
$\mathrm{BE20}$ & - & - & 80 & 20 \\
BE30 & - & - & 70 & 30 \\
BE40 & - & - & 60 & 40 \\
\hline
\end{tabular}

Sample ZYB1 is ZY17 treated in $\mathrm{Bi}_{2} \mathrm{O}_{3}$ atmosphere (see text).

These samples contain a fraction of a monoclinic $\mathrm{ZrO}_{2}$ phase. stainless steel cylinder. Another $\mathrm{Al}_{2} \mathrm{O}_{3}$ ring with a platinum contact $(2)$ is placed on the sensor. The upper gas supply tube (4) and the weight (6) attached to it provide an airtight seal between sensor and ring (3). Sensor and upper ring (2) are surrounded by an $\mathrm{Al}_{2} \mathrm{O}_{3}$-cylinder (7) in order to retain sensor and supply tube (4) in the correct position. An air stream continuously flows through the upper supply tube $\left(2 \mathrm{~cm}^{3} \mathrm{~s}^{-1}\right)$. The gas stream through the lower tube can be switched from air to oxygen and reversely by means of two electrically driven magnetic valves (9). The switching time between these valves is $15 \mathrm{~ms}$. The cell is placed in a tube furnace (10). The sensor voltage as function of time is registered by a Biomation 805 waveform recorder having a maximum sampling speed of one measurement per $10^{-3} \mathrm{~s}$. The voltage signal is followed by an oscilloscope and afterwards indicated on a chart recorder.

\section{Results and discussion}

In Fig. 2 typical response curves are given after step changes from low to high $P_{\mathrm{O}_{2}}(0.21 \rightarrow 1 \mathrm{~atm})$ and from high to low $P_{\mathrm{O}_{2}}(1 \rightarrow 0.21 \mathrm{~atm})$. The sensor voltage as a function of time $(t)$ after a step change in $P_{\mathrm{O}_{2}}, V(t)$, can be described by the empirical relation given by [10]:

$$
V(t)-V(0)=[V(\infty)-V(0)] \exp (-t / \tau)^{1 / 2}
$$

$V(t), V(0)$ and $V(\infty)$ are sensor voltages at $t=t$, $t=0$ and $t=\infty$, respectively. $\tau$ is a characteristic time parameter which follows an Arrhenius-type law [10]:

$$
\tau=A\left(P_{\mathrm{m}}\right)^{-1 / 2} \exp \left(E_{\text {act }} / R T\right)
$$

$A$ is a constant and $P_{\mathrm{m}}$ is the mean oxygen partial pressure, $P_{\mathrm{m}}=[P($ initial $)+P($ final $)] / 2$. In our experiments $P_{\mathrm{m}}$ is constant so a new constant $\tau_{0}=$ $A\left(P_{\mathrm{m}}\right)^{-1 / 2}$, can be introduced in Equation 3. A combination of Equations 2 and 3 gives:

$$
t=\tau_{0} \ln ^{2}\left[1-\frac{V(t)-V(0)}{V(\infty)-V(0)}\right] \exp \left(E_{\mathrm{act}} / R T\right)
$$

In Fig. 3 Equation 4 is fitted for the response data in Fig. 2. It can be seen from Fig. 3 that Equation 4 is in good agreement with our results when $t>0.5 \mathrm{~s}$. The time below which Equation 2 


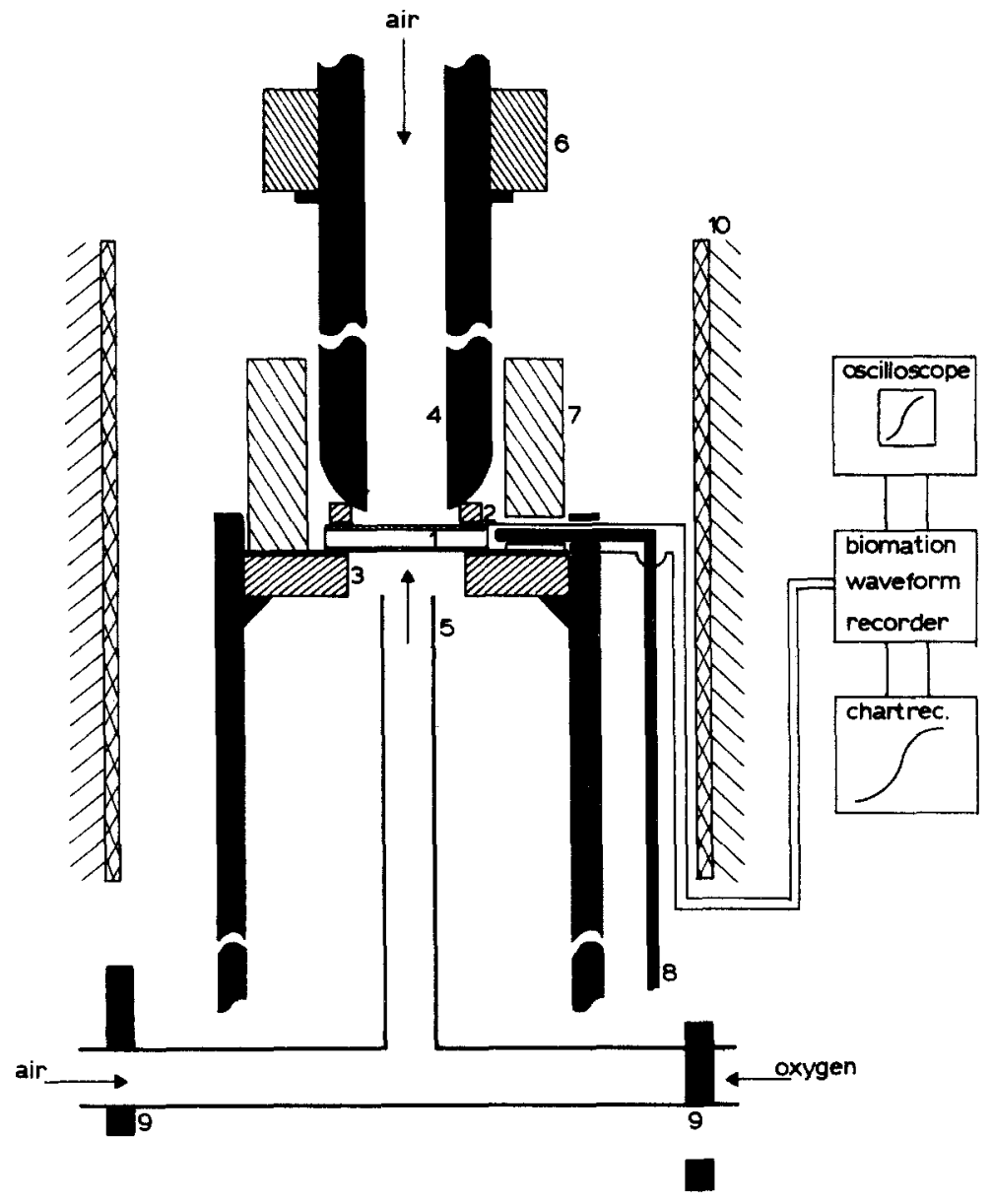

Fig. 1. Cell used in response measurements: 1 . sensor, 2 . and 3. $\mathrm{Al}_{2} \mathrm{O}_{3}$ rings with platinum contacts, 4. and 5. gas supply tubes, 6. weight, 7. $\mathrm{Al}_{2} \mathrm{O}_{3}$ cylinder, 8. thermocouple ( $\mathrm{P}_{\mathrm{t}-}$ Pt $10 \%$ Rh), 9. electrically driven magnetic gas valves, 10. tube furnace wall.

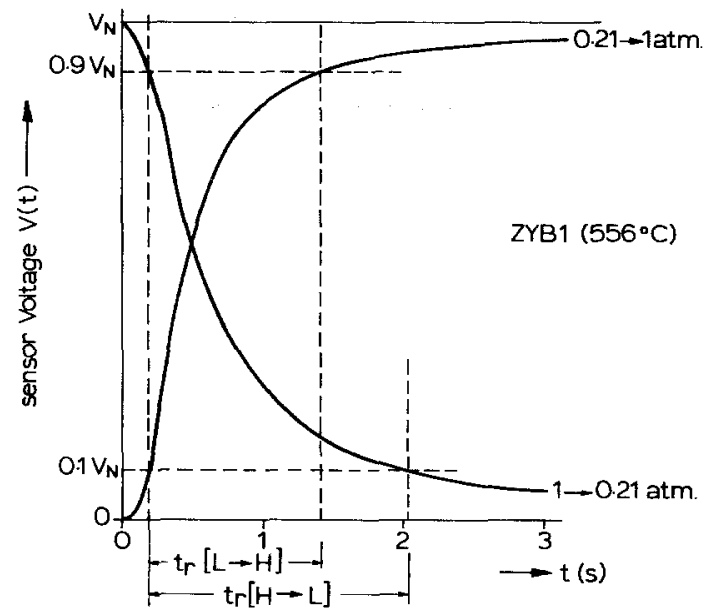

Fig. 2. Response curves after $P_{\mathrm{O}}$ change from 0.21 to 1 atm and reverse. $V_{N}=$ Nernst potential. does not hold $(0.5 \mathrm{~s})$ is independent of temperature. When $t<0.5 \mathrm{~s}, V(t)-V(0)$ is proportional to $\exp (-t / \tau)$. This relation and the independence of the temperature suggests a diffusion and a mixing process of oxygen and air as the rate determining step for $t<0.5 \mathrm{~s}$.

The response time $\left(t_{\mathrm{r}}\right)$ used in this work is defined as:

$$
t_{\mathrm{r}}=t_{0.9}-t_{0.1}
$$

where $t_{0.9}$ and $t_{0.1}$ are the times at which $V(t)=$ $0.9 V(\infty)$ and $V(t)=0.1 V(\infty)$, respectively. The starting point of the measurement is chosen as the time at which $V(t)=0.1 V(\infty)$ because the time delay between $P_{\mathrm{O}_{2}}$ switch and transport to the sensor is difficult to calculate accurately from the experimental curves. It can be seen from 


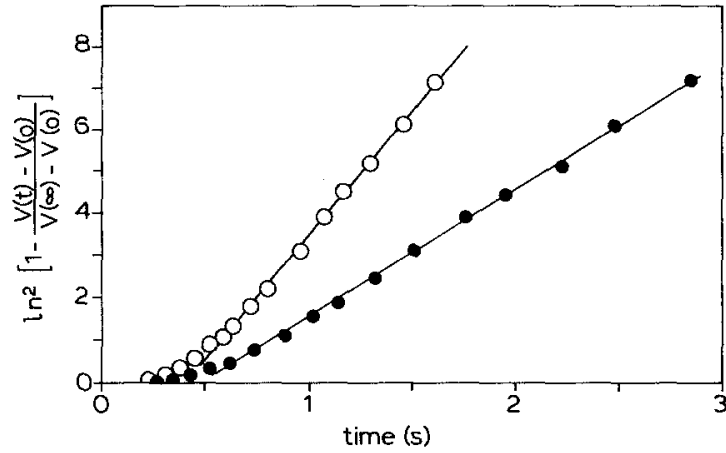

Fig. 3. Voltage variation after $P_{\mathrm{O}}$ step change. Open points: $0.21 \rightarrow 1 \mathrm{~atm}$; closed points $1 \rightarrow 0.21 \mathrm{~atm}$.

Equations 4 and 5 that the time needed to reach the point $0.1 V(\infty)$ is less than $0.5 \%$ of the total response time $\left(t_{\mathbf{r}}\right)$. Equation 4 shows that the choice of the time at which $V(t)=0.9 V(\infty)$ does not affect the value of $E_{\text {act }}$.

It can be seen from Fig. 2 that the value of $t_{\mathrm{r}}$ after a step change from low to high $P_{\mathrm{O}_{2}}$ is smaller than the $t_{\mathrm{r}}$ value after a $P_{\mathrm{O}_{2}}$ step change in the reverse direction $\left(t_{\mathrm{r}}[\mathrm{L} \rightarrow \mathrm{H}]<t_{\mathrm{r}}[\mathrm{H} \rightarrow \mathrm{L}]\right)$. Anderson and Graves [5] and Fouletier et al. [10] found the same type of dependence of $t_{\mathbf{r}}$ on the direction of the oxygen concentration change. Anderson and Graves [5] used normalized functions, $\phi_{V}(t)$ and $\phi_{\mathrm{c}}(t)$, defined by:

$$
\begin{aligned}
\phi_{V}(t) & =\frac{|V(t)-V(\infty)|}{|V(0)-V(\infty)|} \\
\phi_{\mathrm{c}}(t) & =\frac{\left|P_{\mathrm{O}_{2}}(t)-P_{\mathrm{O}_{2}}(\infty)\right|}{\left|P_{\mathrm{O}_{2}}(0)-P_{\mathrm{O}_{2}}(\infty)\right|}
\end{aligned}
$$

Oxygen pressures $P_{\mathrm{O}_{2}}(t)$ at time $t$ used in Equation 7 are derived from experimental $V(t)$ values with the help of Equation 1. In this work an oxygen concentration change from low to high values gave slightly different $\phi_{V}(t)$ as well as $\phi_{c}(t)$ values if these are compared with a concentration change in the reverse direction. Anderson and Graves [5] found $\phi_{\mathbf{c}}(t)$ values independent of the direction of the $P_{\mathrm{O}_{2}}$ changes. According to them [5] this similarity in $\phi_{\mathrm{c}}(t)$ values indicates a diffusive mass transport to or from the electrolyte surface as a rate determining step. The difference in $\phi_{\mathrm{c}}(t)$ values observed for a sensor at a fixed temperature suggests that other processes at the gaselectrode-electrolyte interface play a role in the

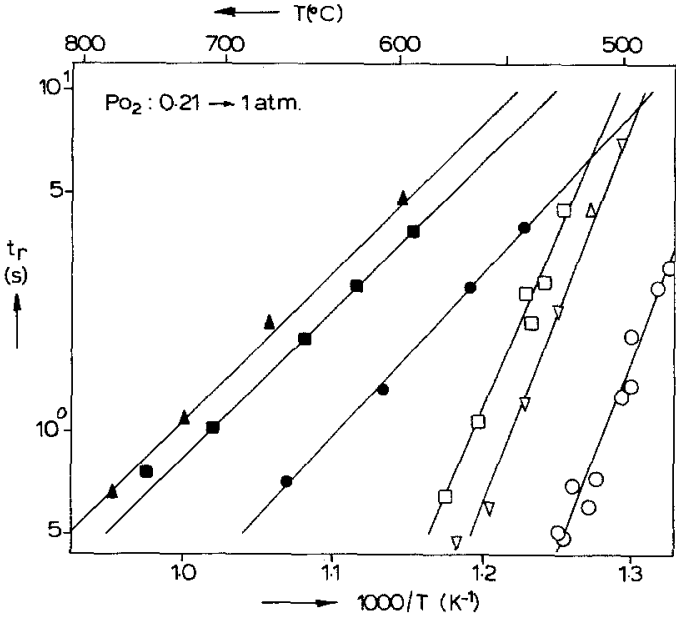

Fig. 4. Response time as a function of temperature for stabilized $\mathrm{ZrO}_{2}$ and stabilized $\mathrm{Bi}_{2} \mathrm{O}_{3} . \nabla-\mathrm{ZY} 17$; 口-ZY21; O - ZY21 (gold electrode); • - BE 20; - $\mathrm{BE} 30 ; \wedge$ - BE40.

response behaviour. This suggestion is supported by the fact that we use porous, thin electrodes (sputtered instead of paste); a factor which eliminates diffusion limitations.

Response times as function of temperature are given in Figs. 4 and 5. It can be seen that the electrolyte material as well as the electrode material influence the response time. The activation energies $\left(E_{\text {act }}\right)$ are calculated from the Arrhenius plots and are given in Table 2. In this table the temperatures are also given at which $t_{\mathrm{r}}$ is $1 \mathrm{~s}$ and

Table 2. Response data after a $\mathrm{P}_{\mathrm{O}_{2}}$ step change from 0.21 to $1 \mathrm{~atm}$

\begin{tabular}{llll}
\hline $\begin{array}{l}\text { Sample } \\
\text { number }\end{array}$ & $\begin{array}{l}\mathrm{E}_{\text {act }} \\
\left(\mathrm{kJ} \mathrm{mol}^{-1}\right)\end{array}$ & $\mathrm{T}_{1}\left({ }^{\circ} \mathrm{C}\right)^{*}$ & $\mathrm{~T}_{10}\left({ }^{\circ} \mathrm{C}\right)^{*}$ \\
\hline ZY17 & 208 & 565 & 490 \\
ZY21 & 199 & 585 & 501 \\
ZY21 (Au) & 216 & 524 & 457 \\
ZYB1 & 156 & 591 & 487 \\
ZYB2 & 130 & 638 & 504 \\
ZYB3 & 169 & 633 & 529 \\
ZYB3 (Au) & 159 & 614 & 505 \\
ZYB4 & 205 & 634 & 550 \\
BE20 & 91 & 688 & 487 \\
BE30 & 84 & 780 & 527 \\
BE40 & 82 & 808 & 543 \\
\hline
\end{tabular}

${ }^{*} T_{1}$ and $T_{10}$ are temperatures at which $t_{\mathrm{r}}$ is 1 and $10 \mathrm{~s}$, respectively.

If not mentioned Pt electrodes were used. 


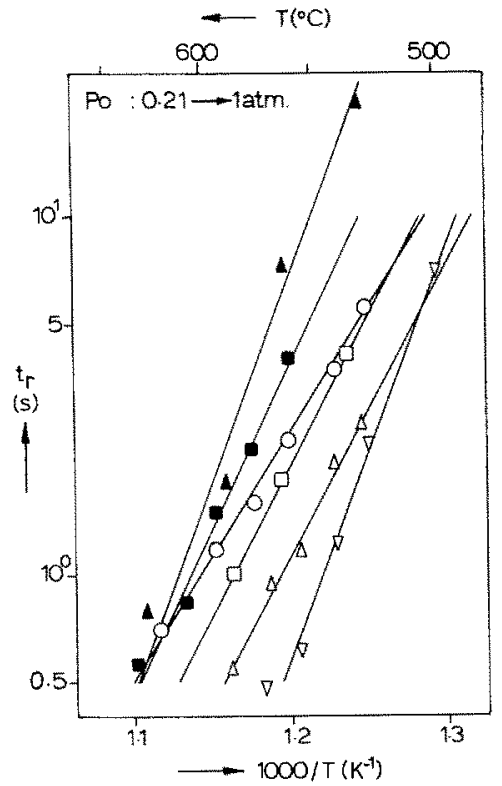

Fig. 5. Response time as a function of temperature for pure and $\mathrm{Bi}_{2} \mathrm{O}_{3}$ doped $\mathrm{ZrO}_{2}-\mathrm{Y}_{2} \mathrm{O}_{3} . \nabla-\mathrm{ZY} 17 ; \triangle-\mathrm{ZYB} 1$; $\circ-Z Y B 2 ;-Z Y B 3 ;-Z Y B 4 ; a-Z Y B 3$ (gold electrode).

$10 \mathrm{~s}$ ( $T_{1}$ and $T_{10}$, respectively). These data enable us to compare the different sensors.

\subsection{Response behaviour of stabilized $\mathrm{ZrO}_{2}$ and $\mathrm{Bi}_{2} \mathrm{O}_{3}$ with Pt electrodes}

The response data for these materials are given in Fig. 4 and Table 2. It can be seen from these results that sensors based on stabilized $\mathrm{ZrO}_{2}$ have a smaller response time compared with stabilized $\mathrm{Bi}_{2} \mathrm{O}_{3}$ in the observed temperature region. At temperatures lower than $500^{\circ} \mathrm{C}$ bismuth oxide materials may be advantageous (see Fig. 4).

The (electrochemical) response time is influenced by at least two factors. First a charge transfer of electrons takes place from the electrode and from the electrolyte to the adsorbed oxygen species (or in the reverse). This results in the formation of a charged (double) layer in the electrolyte region which is directly associated with the electrodes. This region is called the electrode zone with the Debye-Hückel length $L_{\mathrm{D}}$ as characteristic thickness [11]:

$$
L_{\mathrm{D}}=\left(\frac{\epsilon k T}{8 \pi n_{\mathrm{i}} e_{0}^{2}}\right)^{1 / 2}
$$

where $\epsilon$ is the relative dielectric constant, and $n_{i}$ the number of univalent particles per $\mathrm{cm}^{3}$ with positive or negative excess charge in the lattice. The value of $L_{\mathrm{D}}$ can be rather large in these types of material.

In the process described above the rate of oxygen adsorption and the formation rate of the charged layer determines the response time after a $P_{\mathrm{O}_{2}}$ step change. It is suggested in the literature that bismuth sites are active places with regard to oxygen adsorption. This was found in solid electrolytes $[8,12]$ and catalysts such as $\mathrm{BiOBr}[13]$. Therefore in materials having these sites an extra adsorption surface for oxygen is present.

The double layer formation in the electrode zone results in a reorganization in defect structure in this zone without a net change in stoichiometry. The rate of this reorganization can be correlated with the conductivity of the electrode zone. The BE 40 specimen has a lower conductivity than $\mathrm{BE} 30$ while $\mathrm{BE} 20$ has the highest conductivity [7]. Hence within the group of stabilized $\mathrm{Bi}_{2} \mathrm{O}_{3}$ the decrease in response time may be due to a decreasing electrolyte resistance.

The difference in response behaviour between stabilized $\mathrm{Bi}_{2} \mathrm{O}_{3}$ and $\mathrm{ZrO}_{2}$ can be determined by a second process. This will be discussed below.

The second factor which influences the response time is the amount of oxygen species necessary to attain the Nernst e.m.f. Here a change in stoichiometry takes place in the electrode zone by means of redox reactions. This process can be associated with the electrical low frequency capacity $\left(C_{\mathrm{LF}}\right)$ which has the character of a pseudo capacitance. Higher $C_{\mathrm{LF}}$ values result in more oxygen species in the electrode zone which are necessary to attain the final Nernst e.m.f. High $C_{L F}$ values were found for $\mathrm{Bi}_{2} \mathrm{O}_{3}$ specimens [14]. The BE samples have a higher double-layer capacity $\left(C_{\mathrm{DL}}\right)$ than ZY [8]. The high $\left.C_{\mathrm{DL}}>10 \mathrm{~F} \mathrm{~m}^{-2}\right)$ for $\mathrm{BE}$ suggests that no pure $C_{\mathrm{DL}}$ is measured but that a part of it also plays a role in the $C_{\mathrm{LF}}$ process. This $C_{\mathrm{LF}}$ may result in larger response times of stabilized $\mathrm{Bi}_{2} \mathrm{O}_{3}$ compared with stabilized $\mathrm{ZrO}_{2}$ in the observed region.

\subsection{Response behaviour of pure and $\mathrm{Bi}_{2} \mathrm{O}_{3}$ doped $\mathrm{ZrO}_{2}-\mathrm{Y}_{2} \mathrm{O}_{3}$ with $\mathrm{Pt}$ electrodes}

It can be seen from Fig. 5 and Table 2 that $t_{\text {r }}$ 
increases at a fixed temperature when $\mathrm{Bi}_{2} \mathrm{O}_{3}$ is introduced into $\mathrm{ZrO}_{2}-\mathrm{Y}_{2} \mathrm{O}_{3}$ systems. Auger electron spectroscopy measurements on the electrolyte surfaces of the ZYB sensors show an enrichment of bismuth. Surface concentrations of $10-15$ at \% Bi are found for all samples. These bismuth rich surfaces influence the response time in the same way as stabilized $\mathrm{Bi}_{2} \mathrm{O}_{3}$ (see Section 3.1.).

The effect of $\mathrm{Bi}_{2} \mathrm{O}_{3}$ on $t_{x}$ also depends on the phase distribution which may occur after the introduction of $\mathrm{Bi}_{2} \mathrm{O}_{3}$ into $\mathrm{ZY}$. The samples $\mathrm{ZYB} 3$ and $\mathrm{ZYB} 4$ contain monoclinic $\mathrm{ZrO}_{2}$ (respectively, 1 and $21 \mathrm{~mol} \%$ ) while ZYB1 and ZYB2 are cubic and monophasic. The higher the amount of monoclinic zirconia the higher the value of $E_{\text {act }}$ seems to be.

Monoclinic $\mathrm{ZrO}_{2}$ is almost non-ion conducting and has a completely different defect structure compared with cubic ZY. This monoclinic second phase reduces the rate of supply or removal of oxygen species from the electrode zone. The response time of these materials is therefore higher than that for cubic monophasic ZYB specimen. An increase in response time was also found when partially stabilized $\mathrm{ZrO}_{2}$, containing monoclinic $\mathrm{ZrO}_{2}$ as a second phase, was used instead of cubic $\mathrm{ZrO}_{2}$ [15].

\subsection{Comparison of platinum and gold electrodes}

The effect of the electrode materials (platinum and gold) on $t_{\mathbf{r}}$ was studied for ZY21 and ZYB3 (see Figs. 4 and 5 and Table 2). Surprisingly the use of gold electrodes results in a shorter $t_{\mathrm{r}}$. We did not find reports in the literature about the effect of gold electrodes on $t_{\mathrm{r}}$. This effect is now under investigation. Fouletier et al. [10] have studied the response behaviour of $\mathrm{Pt}$ and $\mathrm{Ag}$ electrodes on stabilized $\mathrm{ZrO}_{2}$. Here sensors with $\mathrm{Ag}$ electrodes have lower response times in the temperature region of $300-700^{\circ} \mathrm{C}$.

\section{Conclusions}

The effect of different sensor materials on the response time after a step change in oxygen partial pressure was investigated. Stabilized $\mathrm{Bi}_{2} \mathrm{O}_{3}$ has a larger response time at $T>500^{\circ} \mathrm{C}$ than stabilized $\mathrm{ZrO}_{2}$, despite the lower electrolyte and electrode resistance of $\mathrm{BE}$ solid solutions compared with $\mathrm{ZY}$. The slower response is probably related with the larger low-frequency capacity (pseudocapacity) of $\mathrm{Bi}_{2} \mathrm{O}_{3}$ materials. Introduction of $\mathrm{Bi}_{2} \mathrm{O}_{3}$ into yttria stabilized zirconia results in a longer response time. This effect is more pronounced when a monoclinic $\mathrm{ZrO}_{2}$ phase is present.

Gold electrodes on yttria stabilized zirconia give a considerably better response time than platinum electrodes.

\section{Acknowledgement}

We would like to thank Dr M. J. Verkerk for experiments on stabilized $\mathrm{Bi}_{2} \mathrm{O}_{3}$ materials and for his helpful discussions and suggestions.

\section{References}

[1] R. C. McGeehan, in 'Ceramics in Advanced Energy and Technologies', edited by H. Kröckel, M. Merz and O. van der Biest (D. Reidel Publishing Co., Dordrecht, Boston, Lancaster, 1984) p. 422.

[2] B. C. H. Steele, J. Drennan, R. K. Slotwinsky, N. Bonanos and E. P. Butler, in 'Advanced Ceramics' Vol. 3, edited by A. H. Heuer and L. W. Hobbs (The American Ceramics Society, Columbus, 1981) p. 286.

[3] N. M. Beekmans and L. Heijne, Electrochim. Acta 21 (1976) 303.

[4] L. Heijne and D. den Engelsen, J. Electrochem. Soc. 124 (1977) 727.

[5] J. E. Anderson and Y. B. Graves, J. Appl. Elec trochem. 12 (1982) 335.

[6] J. W. Ross, J. H. Riseman and J. A. Krueger, Pure Appl. Chem. 36 (1973) 473.

[7] M. J. Verkerk, K. Keizer and A. J. Burggraaf, J. Appl. Electrochem. 10 (1980) 81.

[8] M. J. Verkerk, M. W. J. Hammink and A. J. Burggraaf, J. Electrochem. Soc. 130 (1983) 70.

[9] A. J. A. Winnubst and A. J. Burggraaf, Mater. Res. Bull. 19 (1984) 613.

[10] J. Fouletier, H. Seinera and M. Kleitz, J. Appl. Electrochern. 4 (1974) 305.

[11] H. Schmalzried, 'Solid State Reactions', 2nd edn. (Verlag Chemie, Weinheim, 1981) p. 30.

[12] M. J. Verkerk and A. J. Burggraaf, $J$. Electrochem. Soc. 130 (1983) 78.

[13] H. Miura, Y. Arai, K. Sugiyama and T. Matsuda, $J$, Catal. 68 (1981) 264.

[14] H. T. Cahen, PhD thesis, State University Utrecht, The Netherlands (1980).

[15] H. Nakamura and T. Moriya, Solid State Ionics 9-10 (1983) 1257. 